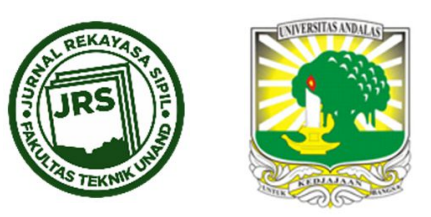

\title{
ANALISIS KESELAMATAN JALAN PADA TIKUNGAN BERDASARKAN JARI-JARI DAN KEMIRINGAN MELINTANG TIKUNGAN
}

\author{
DESI WIDIANTY ${ }^{*}$, ROHANI $^{1}$, IDM ALIT KARYAWAN $^{1}$ \\ ${ }^{1} J u r u s a n$ Teknik Sipil Fakultas Teknik Universitas Mataram \\ *Corresponding author: $ه$ widiantydesi@unram.ac.id
}

Naskah diterima : 11 November 2018. Disetujui: 31 November 2019

\begin{abstract}
ABSTRAK
Jari-jari dan kemiringan melintang tikungan merupakan faktor penyebab terjadinya kecelakaan lalu lintas bila tidak sesuai dengan standar. Ruas jalan Mataram-Senggigi-Pemenang yang menghubungkan antara kota Mataram menuju Pantai Senggigi dan Gili Trawangan banyak dijumpai tikungan tajam dan tanjakan yang tinggi. Tikungan tajam akan mengurangi jarak pandangan pengemudi dan menimbulkan gaya sentrifugal yang besar. Oleh karena itu lokasi ini perlu dilakukan analisis keselamatan terutama pada daerah tikungan yaitu mengetahui besarnya peluang terjadi kecelakaan dan menentukan kategori resiko kecelakaan ditinjau dari jari-jari dan kemiringan melintang tikungan dan selanjutnya dijadikan dasar untuk melakukan penanganan. Parameter yang digunakan meliputi jari-jari tikungan dan kemiringan melintang jalan. Besarnya jari-jari tikungan di lapangan diperoleh dari gambar situasi jalan hasil survay topografi, kemiringan melintang jalan diperoleh dari perbedaan elevasi sisi jalan serta data kecelakaan kecelakaan yang terjadi pada lokasi penelitian. Analisis data berupa analisis jari-jari tikungan, kemiringan melintang jalan, dampak keparahan korban kecelakaan, defisiensi, peluang kecelakaan, kategori resiko kecelakaan lalu lintas. Hasil penelitian didapatkan bahwa, tikungan yang berada di sepanjang ruas jalan Mataram-SenggigiPemenang sebesar $92,85 \%$ memiliki jari-jari tikungan yang berpeluang terjadi kecelakaan antara 10 - 15 kali per tahun. Sebanyak 71,43\% tikungan termasuk kategori sangat berbahaya yaitu Batu Layar (STA 6+400), Batu Bolong (STA7+600), Senggigi Sunset (STA 11+100), Puri Permata (STA 12+900), Sebelum Jembatan (STA 15+600), Setelah Jembatan (STA 15+900), Villa Hantu (STA 18+400), Sebelum Malimbu (STA 18+700), Amarsvati (STA 21+500), dan Nipah (STA 24+000). Akibat faktor kemiringan melintang jalan terdapat 14,29\% tikungan berpeluang terjadi kecelakaan kurang dari 3 kali per tahun serta hanya tikungan Amarsvati (STA 21+500) termasuk kategori cukup berbahaya dan yang lainnya aman. Beberapa solusi untuk mengurangi peluang dan resiko kecelakaan adalah memperbesar jari-jari tikungan, memasang cermin tikungan, rambu pembatas kecepatan, rambu adanya tikungan tajam, lampu penerangan dan guardrail. Khusus tikungan Setelah Malimbu dan Amarsvati juga perlu menaikkan elevasi jalan dari sisi dalam tikungan sehingga kemiringan melintang dibawah $10 \%$. Dari 14 tikungan yang ditinjau secara rata-rata memiliki nilai resiko sebesar 305.71 dengan kategori bahaya, dimana perlu penanganan teknis yang terjadwal maksimum 2 bulan sekali sejak hasil audit disetujui.
\end{abstract}

Kata kunci : Jari-jari tikungan, kemiringan melintang, analisis keselamatan jalan 


\section{PENDAHULUAN}

Salah satu penyebab terjadinya kecelakaan lalu lintas adalah karena faktor geometrik jalan raya. Geometrik jalan berupa lebar, tikungan, landai memanjang, landai melintang, jarak pandang maupun kombinasi dari bagian-bagian tersebut. Pantai Senggigi dan Gili Terawangan merupakan tempat wisata di Lombok yang paling banyak diminati oleh para wisatawan. Pemandangan yang masih alami, asri dan indah menjadi daya pikat dan alasan kunjungannya. Ruas jalan Mataram-Senggiri-Pemenang menjadi jalan akses menuju ke obyek wisata tersebut. Berada di didaerah perbukitan, menyebabkan ruas jalan ini harus mengikuti topografi tanah yang ada, akibatnya banyak dijumpai tikungan yang tajam dan tanjakan yang cukup tinggi. Ketajaman dari suatu tikungan akan mempengaruhi kemudahan pengemudi untuk bisa mempertahankan kendaraannya tetap pada lajurnya. Semakin kecil jari-jari tikungan akan semakin sulit dilalui oleh pengemudi menggunakan kecepatan rencana, dimana untuk jalan kolektor primer sebesar $60 \mathrm{~km} / \mathrm{jam}$. Hal ini disebabkan karena jarak pandangan pengemudi menjadi lebih pendek serta gaya sentifugal yang timbul juga semakin besar. Gaya senrifugal di daerah tikungan dapat diimbangi dengan memberikan kemiringan melintang jalan atau superelevasi. Superelevasi sangat dipengaruhi oleh jari-jari tikungan dan kecepatan rencana, superelavasi maksimum akan menghasilkan tikungan yang tajam dengan jari-jari minimum. Kendaraan yang bergerak lebih rendah dari kecepatan yang direncanakan akan mengganggu kendaraan yang bergerak di belakangnya. Perbedaan dimensi atau hasil ukur di lapangan dengan persyaratan yang dibutuhkan akan menyebabkan timbulnya peluang terjadi kecelakaan lalu lintas. Oleh karena itu perlu dilakukan analisis keselamatan pada daerah tikungan yaitu mengetahui besarnya peluang terjadi kecelakaan dan menentukan kategori resiko kecelakaan ditinjau dari jari-jari dan kemiringan melintang tikungan dan selanjutnya dijadikan dasar untuk melakukan penanganan.

\section{TIKUNGAN DAN KECELAKAAN LALULINTAS}

Karyawan and Widianty (2014) mendapatkan bahwa tikungan di ruas jalan SenggigiLembar sebagian besar tikungannya memiliki jarak pandangan henti yang tidak memenuhi persyaratan atau jarak pandangan henti yang tersedia lebih kecil dari pada yang dibutuhkan, sehingga pengendara harus menurunkan kecepatan kendaraannya ketika masuk ke daerah tikungan.

Pada lokasi tikungan yang sama, Karyawan, Widianty, and Sideman (2015) berdasarkan kecepatan rencana dan kecepatan lapangan, sebagian besar kelandaian melintang yang tersedia dilapangan lebih kecil dibandingkan dengan kelandaian melintang hasil analisis, sehingga tikungan kurang mampu secara maksimal mereduksi gaya sentrifugal yang timbul.

Widianty and Alit (2017) melakukan audit keselamatan di ruas jalan Senggigi-Pemenang menggunakan nilai defisiensi yaitu prosentase perbandingan ketersediaan di lapangan dengan persyaratan yang dibutuhkan. Parameter jarak pandangan henti menyebabkan lokasi berpeluang terjadi kecelakaan sebanyak 3-15 kali per tahun dan 50\% lokasi beresiko sangat berbahaya. Kondisi perkerasan jalan juga berpeluang terjadi kecelakaan lebih dari 15 kali per tahun dan beresiko sangat berbahaya pada $20 \%$ lokasi. Serta ketersediaan fasilitas pelengkap jalan berpeluang terjadi kecelakaan sebanyak 5-15 kali per tahun dan 60\% beresiko sangat berbahaya.

Penyebab kecelakaan lalulintas di tikungan adalah pengaruh konsistensi desain geometri tikungan yang diwakili oleh nilai Curve Radius Ratio (CRR). Jika rasio radius kurva individual meningkat (mendekati atau lebih dari 1), maka tingkat kecelakaan akan turun. 
Tingkat kecelakaan akan turun jika radius tikungan lebih tinggi daripada rata-rata radius tikungan dari segmen jalan tinjauan, dan akan meningkat ketika radius tikungan lebih rendah daripada rata-rata radius tikungan segmen jalan yang ditinjau Sumarsono, Pramesti, and Sarwono (2010).

Superelevasi adalah kemiringan melintang di tikungan yang berfungsi mengimbangi gaya sentrifugal yang diterima kendaraan pada saat berjalan melalui tikungan dengan kecepatan $\mathrm{V}_{\mathrm{R}}$. Nilai superelevasi maksimum untuk jalan antar kota ditetapkan sebesar $10 \%$ (Departemen Pekerjaan Umum, 1997).

Jari-jari tikungan minimum ditetapkan dengan rumus berikut :

$$
\operatorname{Rmin}=\frac{V^{2}}{127(\text { e maks }+ \text { f maks })}
$$

Dimana $:$ Rmin $=$ Jari-jari minimum $(\mathrm{m}), \mathrm{V}=$ kecepatan rencana $(\mathrm{km} / \mathrm{jam})$, e maks = superelevasi maksimum dan f maks = faktor gesekan samping maksimum.

Kecepatan rencana ditentukan sesuai fungsi jalan dan kondisi medan, dapat dilihat pada Tabel 1.

Tabel 1. Kecepatan Rencana sesuai klasifikasi fungsi dan medan jalan

\begin{tabular}{cccc}
\hline \multirow{2}{*}{ Fungsi } & \multicolumn{3}{c}{ Kecepatan Rencana, $\mathrm{V}_{\mathrm{R}} \mathrm{Km} / \mathrm{jam}$} \\
\cline { 2 - 4 } & Datar & Bukit & Pegunungan \\
\hline Arteri & $70-120$ & $60-80$ & $40-70$ \\
\hline Kolektor & $60-90$ & $50-60$ & $30-50$ \\
\hline Lokal & $40-70$ & $30-50$ & $20-30$ \\
\hline Sumber: Departemen Pekerjaan Umum (1997)
\end{tabular}

Besarnya nilai f maks disajikan pada Tabel 2 berikut :

Tabel 2. Nilai f maks berdasarkan Kecepatan Rencana

\begin{tabular}{cccccccccc}
\hline $\mathrm{V}(\mathrm{km} / \mathrm{j})$ & $\mathbf{4 0}$ & $\mathbf{5 0}$ & $\mathbf{6 0}$ & $\mathbf{7 0}$ & $\mathbf{8 0}$ & $\mathbf{9 0}$ & $\mathbf{1 0 0}$ & $\mathbf{1 1 0}$ & $\mathbf{1 2 0}$ \\
\hline $\mathrm{f}$ & 0.166 & 0.16 & 0.153 & 0.141 & 0.14 & 0.128 & 0.115 & 0.103 & 0.09 \\
\hline \multicolumn{2}{l}{ Sumber : Sukirman (1999) }
\end{tabular}

Kecelakaan merupakan suatu peristiwa di jalan yang tidak diduga dan tidak disengaja melibatkan kendaraan dengan atau tanpa pengguna jalan lain yang mengakibatkan korban manusia dan/atau kerugian harta benda. Sedangkan keselamatan lalu lintas adalah suatu keadaan terhindarnya setiap orang dari resiko kecelakaan selama berlalu lintas yang disebabkan oleh manusia, kendaraan, jalan dan atau lingkungan (UU No. 22 Tahun 2009).

Departemen Pekerjaan Umum (2005), audit keselamatan jalan adalah upaya untuk mencari penyebab terjadinya kecelakaan ataupun masalah-masalah yang terjadi pada jalan rawan kecelakaan agar memberikan keselamatan bagi pengguna jalan. Audit keselamatan jalan merupakan strategi pencegahan kecelakaan lalu lintas dengan pendekatan perbaikan terhadap kondisi desain geometri, bangunan pelengkap jalan, fasilitas pendukung jalan yang berpotensi mengakibatkan konflik lalu lintas dan kecelakaan lalu lintas melalui suatu konsep pemeriksaan jalan yang komprehensif, sistematis dan independen (Departemen Pekerjaan Umum, 2007).

Nilai peluang terjadinya kecelakaan didasarkan pada nilai defisiensi dari data pengukuran di lapangan dan persyaratan yang dibutuhkan. Nilai peluang yang bersifat kualitatif dan kuantitatif telah dibuat oleh A. T. Mulyono, Kushari, and Gunawan (2009) yaitu : 1) 
defisiensi $<10 \%$ mempunyai nilai 1 artinya tidak pernah terjadi kecelakaan ; 2) defisiensi antara 10\% - 40\% mempunyai nilai 2 artinya terjadi kecelakaan sampai 3 kali pertahun ; 3) defisiensi antara 40\% - 70\% mempunyai nilai 3 artinya terjadi kecelakaan 5-10 kali per tahun ; 4) defisiensi antara 70\% - 100\% mempunyai nilai 4 artinya terjadi kecelakaan 10-15 kali per tahun) dan ; 5) defisiensi $>100 \%$ mempunyai nilai 5 artinya terjadi kecelakaan lebih dari 15 kali per tahun.

A. Mulyono, Kushari, Faisol, and Gunawan (2008) juga mendefinisikan nilai dampak keparahan korban kecelakaan berdasarkan pada tingkat fatalitas korban kecelakaan lalu lintas yaitu : 1) bila korban tidak mengalami luka apapun kecuali kerugian material, bernilai 1 dengan kategori amat ringan ; 2) bila korban mengalami luka ringan dan kerugian material, bernilai 10 dengan kategori ringan ; 3) bila korban mengalami luka berat dan tidak berpotensi cacat anggota tubuh, serta ada atau tidak kerugian material, bernilai 40 dengan kategori sedang ; 4) bila korban mengalami luka berat dan berpotensi meninggal dunia dalam proses perawatan di rumah sakit atau tempat penyembuhan, serta ada atau tidak ada kerugian material, bernilai 70 dengan kategori berat ; 5) bila korban meninggal dunia di tempat kejadian kecelakaan, serta ada atau tidak ada kerugian material bernilai 100 dengan kategori amat berat.

Tingkatan resiko kecelakaan ditentukan berdasarkan nilai resiko yang dihasilkan. Nilai resiko kecelakaan didapatkan dari rumus berikut :

$\mathrm{R}=\mathrm{P} \times \mathrm{D}$

Dengan, $\mathrm{R}$ = nilai resiko kecelakaan, $\mathrm{P}=$ nilai peluang kecelakaan, dan $\mathrm{D}=$ nilai dampak keparahan korban kecelakaan. Nilai resiko dan kategori resiko disajikan pada Tabel 3.

Tabel 3. Nilai dan kategori resiko kecelakaan

\begin{tabular}{ccl}
\hline $\begin{array}{c}\text { Nilai resiko } \\
\text { kecelakaan }\end{array}$ & $\begin{array}{c}\text { Kategori } \\
\text { resiko } \\
\text { kecelakaan }\end{array}$ & \multicolumn{1}{c}{ Tingkat penanganan yang diberikan } \\
\hline$<125$ & $\begin{array}{c}\text { Tidak } \\
\text { berbahaya }\end{array}$ & $\begin{array}{l}\text { Monitoring rutin dengan inspeksi keselamatan jalan } \\
\text { yang terjadwal pada titik - titik yang berpotensi } \\
\text { terhadap kejadian kecelakaan. }\end{array}$ \\
\hline $125-250$ & $\begin{array}{c}\text { Cukup } \\
\text { berbahaya }\end{array}$ & $\begin{array}{l}\text { Perlu penanganan teknis yang tidak terjadwal } \\
\text { berdasarkan hasil inspeksi keselamatan jalan di lokasi } \\
\text { kejadian sekitarnya }\end{array}$ \\
\hline $250-375$ & Berbahaya & $\begin{array}{l}\text { Perlu penanganan teknis yang terjadwal maksimum 2 } \\
\text { bulan sekali sejak hasil audit keselamatan jalan } \\
\text { disetujui. }\end{array}$ \\
\hline & Sangat & $\begin{array}{l}\text { Perlu penanganan teknis secara total dengan } \\
\text { stakeholder terkait maksimal 2 (dua) minggu sekali } \\
\text { sejak hasil audit keselamatan jalan disetujui }\end{array}$ \\
\hline
\end{tabular}

Sumber : A. T. Mulyono et al. (2009)

\section{METODOLOGI PENELITIAN}

Lokasi penelitian adalah ruas jalan Senggigi-Pemenang. Berdasarkan surat keputusan gubernur Nusa Tenggara Barat No. 620 - 351 tahun 2016 tentang status ruas jalan provinsi Nusa Tenggara Barat menetapkan bahwa ruas jalan Mataram-Senggigi Pemenang merupakan jalan Kolektor Primer (Pemerintah Kabupaten Lombok Barat, 2011). 


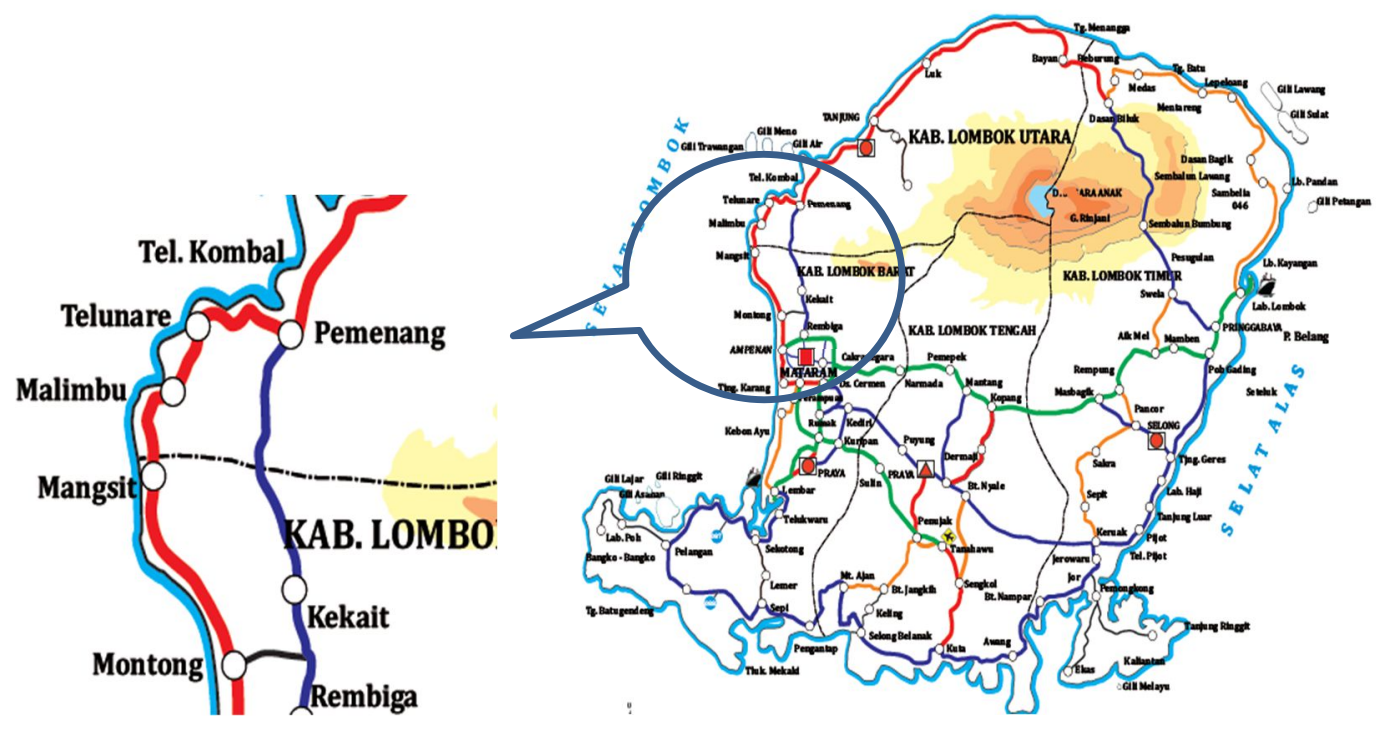

Gambar 1. Lokasi penelitian

Penelitian ini meninjau tikungan-tikungan yang berada di sepanjang ruas jalan MataramSenggigi-Pemenang. Penentuan lokasi dan banyaknya sampel tikungan terlebih dahulu dilakukan survai pendahuluan. Pemilihan didasarkan pada lokasi yang diprediksi berbahaya berdasarkan data kejadian kecelakaan. Dipilih 14 tikungan sebagai sampel untuk di data detail kondisinya. Sampel tikungan tersebut yaitu: Batu Layar, Batu Bolong, Senggigi Sunset, Puri Permata, Katamaran, Jevva Klui, Sebelum Jembatan, Setelah Jembatan, Villa Hantu, Sebelum Malimbu, Malimbu, Setelah Malimbu, Amarsvati dan Nipah.

Pengumpulan data topografi dilakukan dengan survai pengukuran menggunaan alat theodolit. Berdasarkan data pengukuran topografi dilakukan penggambaran kondisi situasi lapangan. Gambar situasi dipakai untuk mengukur jari-jari tikungan yang tersedia di lapangan dengan bantuan autocad. Sedangkan elevasi jalan digunakan untuk menghitung besarnya kemiringan melintang jalan di tikungan.

Audit terhadap infrastruktur jalan dilakukan berdasarkan parameter jari-jari dan kemiringan melintang di tikungan. Analisis data kecelakaan dilakukan untuk menentukan nilai dampak keparahan korban akibat kecelakaan berdasarkan tingkat fatalitas korban kecelakaan (A. T. Mulyono, 2010). Analisis jari-jari dan kemiringan melintang di tikungan dilakukan untuk menentukan nilai defisiensi antara nilai hasil pengukuran di lapangan dengan persyaratan yang dibutuhkan. Hasil analisis defisiensi di tentukan nilai peluang kecelakaan yang dapat ditimbulkan. Kemudian dari nilai peluang dan nilai dampak keparahan korban ditentukan nilai resiko kecelakaan dan sekaligus kategori resiko kecelakaan. Dengan mengetahui kategori resiko yang dapat terjadi, dapat ditentukan langkah atau jenis penanganan yang harus diberikan.

\section{HASIL DAN PEMBAHASAN}

Data kejadian kecelakaan pada masing-masing lokasi dari Kepolisian Resort Lombok Barat dan Lombok Utara dinilai berdasarkan pada tingkat fatalitas korban kecelakaan yaitu meninggal dunia, luka berat dan berpotensi meninggal dunia, luka berat dan berpotensi cacat anggota tubuh, luka ringan dan kerugian material serta tidak mengalami luka dan kerugian material. Berdasarkan data tersebut didapatkan nilai dampak keparahan pada masing-masing tikungan seperti pada Tabel 4. 
Tabel 4. Dampak keparahan korban kecelakaan pada lokasi tikungan

\begin{tabular}{cclccc}
\hline No & $\begin{array}{c}\text { Stationing } \\
\text { Segmen } \\
\text { Jalan }\end{array}$ & Lokasi Tikungan & $\begin{array}{c}\text { Tingkat Fatalitas } \\
\text { Korban } \\
\text { Kecelakaan*) }\end{array}$ & \multicolumn{2}{c}{$\begin{array}{c}\text { Dampak Keparahan } \\
\text { Korban }\end{array}$} \\
\cline { 5 - 6 } & $6+400$ & Batu Layar & Meninggal Dunia & Amat Berat & Nilai \\
Kualitatif & $\begin{array}{c}\text { Nilai } \\
\text { Kuantitatif }\end{array}$ \\
\hline 1 & $7+600$ & Batu Bolong & Meninggal Dunia & Amat Berat & 100 \\
\hline 3 & $11+100$ & Senggigi Sunset & Meninggal Dunia & Amat Berat & 100 \\
\hline 4 & $12+900$ & Puri Permata & Meninggal Dunia & Amat Berat & 100 \\
\hline 5 & $14+700$ & Katamaran & Luka berat & Sedang & 40 \\
\hline 6 & $15+000$ & Jevva Klui & Luka berat & Sedang & 40 \\
\hline 7 & $15+600$ & Sebelum Jembatan & Meninggal Dunia & Amat Berat & 100 \\
\hline 8 & $15+900$ & Setelah Jembatan & Meninggal Dunia & Amat Berat & 100 \\
\hline 9 & $18+400$ & Villa Hantu & Meninggal Dunia & Amat Berat & 100 \\
\hline 10 & $18+700$ & Sebelum Malimbu & Meninggal Dunia & Amat Berat & 100 \\
\hline 11 & $19+300$ & Malimbu & Tidak ada kecelakaan & Tidak Ada & 0 \\
\hline 12 & $20+200$ & Setelah Malimbu & Tidak ada kecelakaan & Tidak Ada & 0 \\
\hline 13 & $21+500$ & Amarsvati & Meninggal Dunia & Amat Berat & 100 \\
\hline 14 & $24+000$ & Nipah & Meninggal Dunia & Amat Berat & 100 \\
\hline
\end{tabular}

Keterangan : *) Sumber Kepolisian Resort Lombok Barat dan Lombok Utara tahun 2013-2017

Data kejadian kecelakaan pada Tabel 4 menunjukkan bahwa kejadian kecelakaan pada sebagian besar segmen jalan tikungan yang ditinjau, mengakibatkan meninggal dunia sehingga dampak keparahan bernilai 100 (amat berat), 2 tikungan berdampak korban mengalami luka berat dan tidak berpotensi cacat anggota tubuh, serta ada atau tidak kerugian material sehingga bernilai 40, dan 2 tikungan tidak pernah terjadi kecelakaan sehingga bernilai 0 .

Besarnya jari-jari tikungan di lapangan diperoleh dengan mengukur diameter tikungan pada peta situasi jalan yang merupakan hasil dari pengukuran theodolite menggunakan bantuan autocad. Gambar 2 menunjukkan bahwa hasil ukur diameter tikungan Batu Layar sebesar 31,32 meter, berarti tikungan ini mempunyai jari-jari lapangan sebesar 15,66 dibulatkan 16 meter.

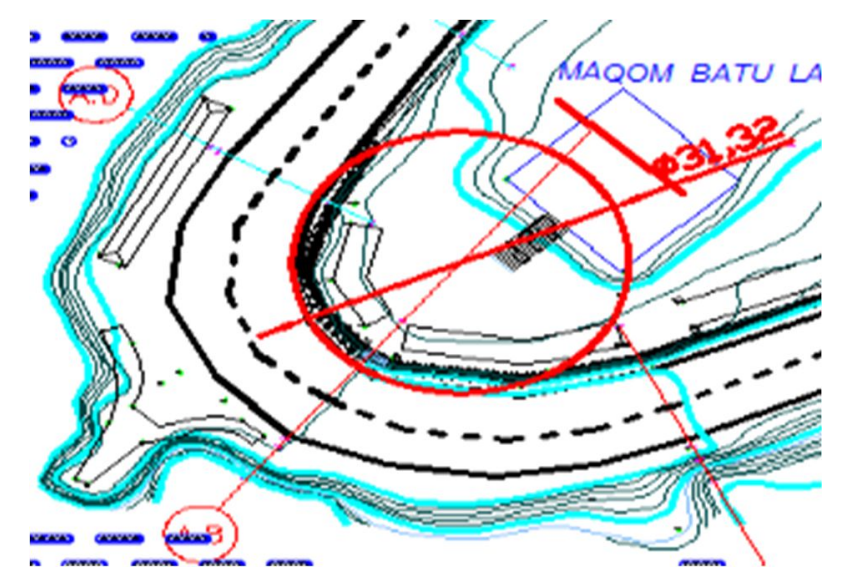

Gambar 2. Hasil ukur diameter tikungan Batu Layar

Kecepatan rencana jalan kolektor dengan medan berbukit berdasarkan Tabel 1 sebesar 50 $60 \mathrm{~km} / \mathrm{jam}$, agar dapat memberikan layanan yang lebih baik maka diambil sebesar 60 $\mathrm{km} / \mathrm{jam}$. Sedangkan besarnya superelevasi maksimum untuk jalan antar kota adalah $10 \%$ 
dan faktor gesekan samping untuk kecepatan $60 \mathrm{~km} / \mathrm{jam}$ pada Tabel 3 sebesar 0,153. Nilai jari-jari minimum dihitung menggunakan rumus (1) berikut :

$$
\operatorname{Rmin}=\frac{V^{2}}{127(\text { e maks }+f \text { maks })}=\frac{60^{2}}{127(0,10+0,153)}=112 \text { meter }
$$

Nilai kemiringan melintang (superelevasi) dilapangan untuk tikungan Batu Layar didapatkan dari :

$$
\text { elap }=\frac{\text { elev sisi luar }- \text { elev sisi dalam }}{\text { lebar jalan }} \times 100 \%=\frac{16,81-16,03}{10,30} \times 100 \%=7,57 \%
$$

Defisiensi yang ditimbulkan merupakan perbedaan hasil ukur di lapangan dengan syarat yang diperlukan terhadap syarat yang dibutuhkan akan mendapatkan defisiensi yang ditimbulkan.

Data jari-jari dan kemiringan melintang di tikungan dari pengukuran peta situasi serta besarnya defisiensi berdasarkan jari-jari dan kemiringan melintang di tikungan disajikan pada Tabel 5 .

\begin{tabular}{|c|c|c|c|c|c|c|c|c|}
\hline No & STA & Nama Tikungan & $\begin{array}{l}\text { Rlap } \\
(\mathrm{m})\end{array}$ & $\begin{array}{c}\text { Rmi } \\
\text { n } \\
(\mathrm{m})\end{array}$ & $\begin{array}{l}\text { Defisiensi } \\
\text { R \% }\end{array}$ & $\underset{\%}{\text { e lap }}$ & $\begin{array}{c}\mathrm{e} \\
\mathrm{maks} \\
\%\end{array}$ & $\begin{array}{l}\text { Defisiensi } \\
\text { e \% }\end{array}$ \\
\hline 1 & $6+400$ & Batu Layar & 16 & 112 & 86.02 & 7.57 & 10 & 0.00 \\
\hline 2 & $7+600$ & Batu Bolong & 28 & 112 & 75.21 & 2.37 & 10 & 0.00 \\
\hline 3 & $11+100$ & Senggigi Sunset & 13 & 112 & 88.16 & 5.31 & 10 & 0.00 \\
\hline 4 & $12+900$ & Puri Permata & 8 & 112 & 92.43 & 8.14 & 10 & 0.00 \\
\hline 5 & $14+700$ & Katamaran & 18 & 112 & 83.82 & 6.45 & 10 & 0.00 \\
\hline 6 & $15+000$ & Jevva Klui & 37 & 112 & 67.16 & 10.86 & 10 & 8.62 \\
\hline 7 & $15+600$ & Sebelum Jembatan & 17 & 112 & 84.87 & 5.02 & 10 & 0.00 \\
\hline 8 & $15+900$ & Setelah Jembatan & 18 & 112 & 83.90 & 4.07 & 10 & 0.00 \\
\hline 9 & $18+400$ & Villa Hantu & 9 & 112 & 91.66 & 6.58 & 10 & 0.00 \\
\hline 10 & $18+700$ & Sebelum Malimbu & 29 & 112 & 73.82 & 0.72 & 10 & 0.00 \\
\hline 11 & $19+300$ & Malimbu & 16 & 112 & 85.64 & 4.46 & 10 & 0.00 \\
\hline 12 & $20+200$ & Setelah Malimbu & 24 & 112 & 78.70 & 11.70 & 10 & 17.04 \\
\hline 13 & $21+500$ & Amarsvati & 23 & 112 & 79.36 & 12.60 & 10 & 26.00 \\
\hline 14 & $24+000$ & Nipah & 33 & 112 & 70.49 & 3.00 & 10 & 0.00 \\
\hline
\end{tabular}

Tabel 5. Defisiensi Jari-jari (R) dan kemiringan melintang (e) tikungan

Hasil perhitungan defisiensi berdasarkan parameter jari-jari tikungan didapatkan bahwa semua tikungan mempunyai jari-jari yang lebih kecil dari jari-jari minimum artinya semua tikungan tidak memenuhi persyaratan. Semua tikungan yang ditinjau merupakan tikungantikungan yang sangat tajam karena memiliki jari-jari tikungan yang kecil. Sedangkan berdasarkan kemiringan melintang jalan didapatkan bahwa 78,57\% segmen jalan tikungan sudah memenuhi persyaratan, hanya $21,43 \%$ lokasi tikungan yang memiliki defisiensi yaitu sebesar $8,62 \%$ - $26 \%$. Nilai defisiensi yang dihasilkan digunakan untuk mengetahui seberapa besar suatu tikungan berpeluang menimbulkan kecelakaan. Besarnya nilai peluang timbulnya kecelakaan yang diakibatkan karena adanya defisiensi jari-jari dan kemiringan melintang di tikungan disajikan pada Tabel 6. 
Tabel 6. Peluang kejadian kecelakaan berdasarkan defisiensi Jari-jari dan kemiringan melintang

\begin{tabular}{|c|c|c|c|c|c|c|c|}
\hline \multirow{2}{*}{ No } & \multirow{2}{*}{ STA } & \multirow{2}{*}{ Lokasi Tikungan } & \multicolumn{2}{|c|}{ Jari-jari (R) } & \multicolumn{2}{|c|}{$\begin{array}{c}\text { Kemiringan } \\
\text { melintang (e) }\end{array}$} & \multirow{2}{*}{$\begin{array}{c}\text { Nilai Peluang } \\
\text { akibat } \\
\text { Defisiensi R } \\
\text { dan e } \\
\end{array}$} \\
\hline & & & $\begin{array}{l}\text { Defisie } \\
\text { nsi (\%) }\end{array}$ & Peluang & $\begin{array}{l}\text { Defisie } \\
\text { nsi (\%) }\end{array}$ & Peluang & \\
\hline 1 & $6+400$ & Batu Layar & 86.02 & 4 & 0.00 & 1 & 4 \\
\hline 2 & $7+600$ & Batu Bolong & 75.21 & 4 & 0.00 & 1 & 4 \\
\hline 3 & $11+100$ & Senggigi Sunset & 88.16 & 4 & 0.00 & 1 & 4 \\
\hline 4 & $12+900$ & Puri Permata & 92.43 & 4 & 0.00 & 1 & 4 \\
\hline 5 & $14+700$ & Katamaran & 83.82 & 4 & 0.00 & 1 & 4 \\
\hline 6 & $15+000$ & Jevva Klui & 67.16 & 3 & 8.62 & 1 & 3 \\
\hline 7 & $15+600$ & Sebelum Jembatan & 84.87 & 4 & 0.00 & 1 & 4 \\
\hline 8 & $15+900$ & Setelah Jembatan & 83.90 & 4 & 0.00 & 1 & 4 \\
\hline 9 & $18+400$ & Villa Hantu & 91.66 & 4 & 0.00 & 1 & 4 \\
\hline 10 & $18+700$ & Sebelum Malimbu & 73.82 & 4 & 0.00 & 1 & 4 \\
\hline 11 & $19+300$ & Malimbu & 85.64 & 4 & 0.00 & 1 & 4 \\
\hline 12 & $20+200$ & Setelah Malimbu & 78.70 & 4 & 17.04 & 2 & 4 \\
\hline 13 & $21+500$ & Amarsvati & 79.36 & 4 & 26.00 & 2 & 4 \\
\hline 14 & $24+000$ & Nipah & 70.49 & 4 & 0.00 & 1 & 4 \\
\hline
\end{tabular}

Nilai peluang yang dihasilkan pada Tabel 6 dengan parameter jari-jari menunjukkan bahwa dari 14 tikungan yang ditinjau 92,86\% tikungan mempunyai peluang terjadi kecelakaan dengan nilai 4 yang berarti tikungan tersebut berpotensi terjadi kecelakaan 10 - 15 kali pertahun. Sedangkan 1 tikungan yaitu Jevva Klui bernilai 3 yang berpotensi terjadi kecelakaan 5 - 10 kali pertahun. Hal ini terjadi dikarenakan semua tikungan memiliki jarijari tikungan yang jauh lebih kecil dari yang disyaratkan. Jari-jari yang kecil menyebabkan jarak pandangan pengemudi menjadi lebih pendek sehingga pengemudi akan kesulitan untuk tetap berada pada lajurnya dengan menggunakan kecepatan rencana.

Nilai peluang yang diakibatkan karena adanya defisiensi dari parameter kemiringan melintang didapatkan bahwa $85,71 \%$ tikungan tidak berpeluang menimbulkan kecelakaan dan 2 tikungan hanya berpeluang kurang dari 3 kali per tahun terjadi kecelakaan. Hal ini disebabkan karena nilai kemiringan melintang di tikungan sebagian besar memenuhi persyaratan dari e maksimum. Kondisi ini menunjukkan bahwa gaya sentrifugal yang diterima oleh kendaraan akibat tikungan bisa diimbangi dengan adanya kemiringan melintang atau superelevasi.

Namun jika kedua parameter tersebut berada pada kondisi bersamaan maka peluang yang terjadi adalah nilai peluang maksimum dari 2 parameter tersebut. Nilai peluang kecelakaan yang diakibatkan oleh defisiensi jari-jari dan kemiringan melintang di tikungan disajikan pada Tabel 6. Karena parameter jari-jari memiliki defisiensi yang lebih besar dibandingkan kemiringan melintang sehingga peluang kecelakaan sama seperti karena parameter jari-jari, yaitu dari 14 tikungan yang ditinjau $92,85 \%$ tikungan mempunyai peluang terjadi kecelakaan dengan nilai 4 yang berpotensi terjadi kecelakaan 10 - 15 kali pertahun. Sedangkan 1 tikungan yaitu Jevva Klui bernilai 3 berpotensi terjadi kecelakaan $5-10$ kali pertahun.

Nilai resiko kecelakaan suatu lokasi dapat diketahui dari perkalian antara nilai dampak keparahan korban kecelakaan (Tabel 4) dengan nilai peluang kecelakaan akibat defisiensi (Tabel 6). Hasil dari nilai resiko tersebut dapat diketahui kelompok atau kategori resiko kecelakaan. Kategori resiko ini akan dijadikan pedoman untuk usaha penanganan jalan 
selanjutnya. Nilai dan kategori resiko yang ditimbulkan untuk semua tikungan dengan parameter jari-jari dan kemiringan melintang di tikungan disajikan pada Tabel 7 .

Tabel 7. Resiko kecelakaan berdasarkan parameter jari-jari dan kemiringan melintang

\begin{tabular}{|c|c|c|c|c|c|c|c|}
\hline \multirow[b]{2}{*}{ No } & \multirow[b]{2}{*}{$\begin{array}{c}\text { Lokasi } \\
\text { Tikungan }\end{array}$} & \multicolumn{3}{|c|}{ Jari-jari } & \multicolumn{3}{|c|}{ Kemiringan melintang } \\
\hline & & $\begin{array}{c}\text { Nilai } \\
\text { Dampak }\end{array}$ & $\begin{array}{c}\text { Nilai } \\
\text { Resiko }\end{array}$ & Kategori Resiko & $\begin{array}{c}\text { Nilai } \\
\text { Dampak }\end{array}$ & $\begin{array}{c}\text { Nilai } \\
\text { Resiko }\end{array}$ & Kategori Resiko \\
\hline 1 & $6+400$ & 100 & 400 & Sangat Berbahaya & 100 & 100 & Tidak Berbahaya \\
\hline 2 & $7+600$ & 100 & 400 & Sangat Berbahaya & 100 & 100 & Tidak Berbahaya \\
\hline 3 & $11+100$ & 100 & 400 & Sangat Berbahaya & 100 & 100 & Tidak Berbahaya \\
\hline 4 & $12+900$ & 100 & 400 & Sangat Berbahaya & 100 & 100 & Tidak Berbahaya \\
\hline 5 & $14+700$ & 40 & 160 & Cukup Berbahaya & 40 & 40 & Tidak Berbahaya \\
\hline 6 & $15+000$ & 40 & 120 & Tidak Berbahaya & 40 & 40 & Tidak Berbahaya \\
\hline 6 & $15+600$ & 100 & 400 & Sangat Berbahaya & 100 & 100 & Tidak Berbahaya \\
\hline 8 & $15+900$ & 100 & 400 & Sangat Berbahaya & 100 & 100 & Tidak Berbahaya \\
\hline 9 & $18+400$ & 100 & 400 & Sangat Berbahaya & 100 & 100 & Tidak Berbahaya \\
\hline 10 & $18+700$ & 100 & 400 & Sangat Berbahaya & 100 & 100 & Tidak Berbahaya \\
\hline 11 & $19+300$ & 0 & 0 & Tidak Berbahaya & 0 & 0 & Tidak Berbahaya \\
\hline 12 & $20+200$ & 0 & 0 & Tidak Berbahaya & 0 & 0 & Tidak Berbahaya \\
\hline 13 & $21+500$ & 100 & 400 & Sangat Berbahaya & 100 & 200 & Cukup Berbahaya \\
\hline 14 & $24+000$ & 100 & 400 & Sangat Berbahaya & 100 & 100 & Tidak Berbahaya \\
\hline
\end{tabular}

Nilai resiko berdasarkan parameter jari-jari tikungan dari Tabel 7 menunjukkan bahwa $71,43 \%$ lokasi tikungan memiliki nilai resiko sebesar 400 yang berarti tikungan termasuk kategori resiko sangat berbahaya. Sedangkan 2 lokasi tikungan yaitu STA $14+700$ (Katamaran ) dan STA 15+000 (Jevva klui) walaupun memiliki nilai peluang yang besar namun karena di 2 lokasi tersebut tingkat fatalitas korban kecelakaan tidak sampai meninggal dunia hanya mengalami luka berat dan tidak berpotensi cacat anggota tubuh, sehingga nilai dampak kecelakaan nya hanya 40. Hal ini menyebabkan lokasi tikungan ini termasuk kategori tidak berbahaya dan cukup berbahaya. Sama halnya untuk lokasi tikungan pada STA 19+300 (Malimbu) dan STA 20+200 (Setelah Malimbu), walaupun peluang kecelakaan akibat defisiensi besar tapi karena di 2 lokasi tikungan tidak pernah terjadi kecelakaan maka nilai resiko nya menjadi 0 dan memiliki kategori tidak berbahaya.

Nilai resiko berdasarkan parameter kemiringan melintang dihasilkan antara $0-100$ sebanyak 92,86\% memiliki kategori tidak berbahaya dan 1 tikungan yaitu tikungan Amarsvati mempunyai nilai resiko 200 dengan kategori cukup berbahaya. Dari kondisi ini menunjukkan bahwa selain faktor peluang yang diakibatkan adanya defisiensi dari parameter penyebab kecelakaan, namun data dari nilai keparahan korban kecelakaan juga sangat mempengaruhi besar dan tingkat kategori resiko yang dapat timbul. Sehingga keberadaan data kecelakaan sangat mempengaruhi nilai dan kategori resiko.

Jika parameter jari-jari dan kemiringan melintang di tikungan berada pada kondisi bersamaan maka nilai resiko yang terjadi adalah nilai resiko yang paling tinggi dari kedua parameter yang dihasilkan. Nilai resiko kecelakaan yang dapat ditimbulkan akibat defisiensi jari-jari dan kemiringan melintang di tikungan disajikan pada Tabel 8.

Tabel 8 menunjukkan bahwa tikungan yang ada pada ruas jalan Mataram-SenggigiPemenang mempunyai nilai resiko 400 (nilai resiko $>375$ ) dengan kategori sangat berbahaya sebanyak 10 tikungan (71,43\%). Nilai resiko 160 (nilai resiko antara $125-250$ ) dengan kategori cukup berbahaya sebanyak 1 tikungan (7,14\%) dan nilai resiko 0 - 120 (nilai resiko < 125) dengan kategori tidak berbahaya sebanyak 3 tikungan. Secara keseluruhan tikungan pada ruas jalan Mataram-Senggigi-Pemenang mempunyai nilai resiko rata-rata 
sebesar 305.71 dengan kategori Berbahaya. Kategori berbahaya perlu penanganan teknis yang terjadwal maksimum 2 bulan sekali sejak hasil audit keselamatan jalan disetujui.

Tikungan Batu Layar, Batu Bolong, Senggigi Sunset, Puri Permata, Sebelum Jembatan, Setelah Jembatan, Villa Hantu, Sebelum Malimbu, Amarsvati, dan Nipah ditinjau dari parameter jari-jari dan kemiringan melintang mempunyai kategori sangat berbahaya. Tingkat penanganan yang perlu dilakukan adalah penanganan teknis secara total suatu tikungan jalan, besarnya jari-jari tikungan seharusnya tidak boleh kurang dari R minimum karena dapat membahayakan pengemudi kendaraan untuk bergerak dengan kecepatan rencana. Hal ini dikarenakan semakin kecil jari-jari tikungan maka semakin pendek jarak pandangan pengemudi sehingga jarak pandangan pengemudi menjadi terbatas untuk melihat penghalang yang ada di depannya.

Tabel 8. Resiko kecelakaan maksimum berdasarkan jari-jari dan kemiringan melintang tikungan

\begin{tabular}{cclcccc}
\hline \multirow{2}{*}{ No } & STA & Lokasi Tikungan & \multicolumn{2}{c}{ Nilai Resiko } & $\begin{array}{c}\text { Nilai } \\
\text { Resiko } \\
\text { Maks }\end{array}$ & Kategori Resiko \\
\hline 1 & $6+400$ & Batu Layar & 400 & 100 & 400 & Sangat Berbahaya \\
\hline 2 & $7+600$ & Batu Bolong & 400 & 100 & 400 & Sangat Berbahaya \\
\hline 3 & $11+100$ & Senggigi Sunset & 400 & 100 & 400 & Sangat Berbahaya \\
\hline 4 & $12+900$ & Puri Permata & 400 & 100 & 400 & Sangat Berbahaya \\
\hline 5 & $14+700$ & Katamaran & 160 & 40 & 160 & Cukup Berbahaya \\
\hline 6 & $15+000$ & Jevva Klui & 120 & 40 & 120 & Tidak Berbahaya \\
\hline 7 & $15+600$ & Sebelum Jembatan & 400 & 100 & 400 & Sangat Berbahaya \\
\hline 8 & $15+900$ & Setelah Jembatan & 400 & 100 & 400 & Sangat Berbahaya \\
\hline 9 & $18+400$ & Villa Hantu & 400 & 100 & 400 & Sangat Berbahaya \\
\hline 10 & $18+700$ & Sebelum Malimbu & 400 & 100 & 400 & Sangat Berbahaya \\
\hline 11 & $19+300$ & Malimbu & 0 & 0 & 0 & Tidak Berbahaya \\
\hline 12 & $20+200$ & Setelah Malimbu & 0 & 0 & 0 & Tidak Berbahaya \\
\hline 13 & $21+500$ & Amarsvati & 400 & 200 & 400 & Sangat Berbahaya \\
\hline 14 & $24+000$ & Nipah & 400 & 100 & 400 & Sangat Berbahaya \\
\hline & & & Rata-Rata Nilai Resiko & 305,71 & BERBAHAYA \\
\hline
\end{tabular}

Upaya-upaya yang dapat dilakukan untuk mengurangi peluang dan resiko kecelakaan adalah memperbesar jari-jari tikungan, memberi rambu cermin tikungan agar jarak pandangan pengemudi menjadi lebih panjang, memberi rambu batas kecepatan supaya pengemudi dapat mengurangi kecepatan sebelum masuk ke tikungan, memberi rambu peringatan tikungan tajam supaya ada pemberitahuan bahwa ada tikungan yang tajam sehingga pengemudi tidak kaget ketika memasuki daerah tikungan, memasang lampu penerangan agar pada malam hari dan waktu hujan bisa terlihat, memberikan guardrail (pengaman tepi jalan) agar tepi jalan terlindungi. Tikungan yang beresiko sangat berbahaya diperlukan penanganan teknis secara total dengan stakeholder terkait maksimal 2 (dua) minggu sekali sejak hasil audit keselamatan jalan disetujui. Sedangkan penanganan yang perlu dilakukan pada parameter kemiringan melintang yaitu pada tikungan Jevva Klui, Setelah Malimbu dan Amarsvati dengan menaikkan elevasi dari sisi dalam tikungan jalan sehingga kemiringan melintang (superelevasi) menjadi kurang dari $10 \%$. Walaupun dari kategori resiko yang dihasilkan menunjukkan bahwa ketiga lokasi tikungan tidak beresiko terjadi kecelakaan yang disebabkan karena dari data kecelakaan lokasi tersebut tidak pernah terjadi kecelakaan lalu lintas. Monitoring rutin dengan inspeksi keselamatan jalan yang terjadwal pada ketiga tikungan ini harus tetap dilakukan. 


\section{SIMPULAN DAN SARAN}

\subsection{Simpulan}

Nilai Peluang terjadi kecelakaan akibat defisiensi jari-jari dan kemiringan melintang pada tikungan sepanjang ruas jalan Mataram-Senggigi-Pemenang 92,86\% bernilai 4 yang artinya tikungan berpeluang terjadi kecelakaan 10 - 15 kali per tahun. Hanya tikungan Jevva Klui bernilai 3 yang berpotensi terjadi kecelakaan 5 - 10 kali pertahun. Dari 14 tikungan yang ditinjau, resiko yang dapat ditimbulkan oleh kondisi jalan tersebut rata-rata bernilai 305.71 dengan kategori bahaya, dimana perlu penanganan teknis yang terjadwal maksimum 2 bulan sekali sejak hasil audit keselamatan jalan disetujui. Jenis penanganan yang harus dilakukan pada tikungan di sepanjang ruas jalan Mataram-Senggigi-Pemenang adalah memperbesar jari-jari tikungan, memberi rambu cermin tikungan, rambu kurangi kecepatan, rambu adanya tikungan tajam, lampu penerangan dan guardrail, menaikkan elevasi dari sisi dalam tikungan sehingga kemiringan melintang $<10 \%$.

\subsection{Saran}

Disarankan bagi pihak stakeholder yaitu dinas pekerjaan umum dan dinas perhubungan segera memberikan perhatian dan menindaklanjuti penanganan terhadap tikungan pada ruas jalan Mataram-Senggigi-Pemenang karena secara rata-rata tikungan mempunyai resiko berbahaya mengingat ruas jalan ini menjadi jalan akses ke obyek wisata di Senggigi dan Gili Terawangan.

\section{UCAPAN TERIMAKASIH}

Kami mengucapkan terima kasih yang sebesar-besarnya kepada DRPM Ditjen Penguatan Ristek dan Pengembangan Kemenriktek Dikti yang telah membantu dana penelitian melalui Penelitian Produk Terapan 2017 dan Penelitian Strategis Nasional Institusi (2018). Demikian pula pada Erni Ermayani dan Ika Yuni Prihatin yang telah membantu dalam pelaksanaan penelitian ini.

\section{DAFTAR PUSTAKA}

Departemen Pekerjaan Umum. (1997). Tata Cara Perencanaan Geometrik Jalan Antar Kota. Jakarta: Direktorat Jenderal Bina Marga.

Departemen Pekerjaan Umum. (2005). Pedoman Konstruksi dan Bangunan, Audit Keselamatan Jalan. Jakarta: Pd T-17-2005-B.

Departemen Pekerjaan Umum. (2007). Modul Pelatihan Inspeksi Keselamatan Jalan (IKJ) dalam Penyelenggaraan Jalan Berkeselamatan. Jakarta: Direktorat Jenderal Bina Marga.

Karyawan, I. D. M. A., \& Widianty, D. (2014). Analisis jarak pandang henti sebagai elemen geometrik pada beberapa tikungan ruas Jalan Mataram-Lembar. Jurnal Penelitian UNRAM, 18(2), 40-48.

Karyawan, I. D. M. A., Widianty, D., \& Sideman, I. A. O. S. (2015). Analisis Kelandaian Melintang sebagai Elemen Geometrik pada Beberapa Tikungan Ruas Jalan Mataram-Lembar. Spektrum Sipil, 2(1), 12-21.

Mulyono, A., Kushari, B., Faisol, K., \& Gunawan, H. (2008). Modul Pelatihan Inspeksi Keselamatan Jalan (IKJ) dalam Penyelenggaraan Jalan Berkeselamatan. Paper presented at the FSTPT (Forum Studi Transportasi antar Perguruan Tinggi), Semarang.

Mulyono, A. T. (2010). Penyusunan Model Audit Defisiensi Keselamatan Infrastruktur Jalan untuk Mengurangi Potensi Tejadinya Kecelakaan Berkendaraan. Retrieved from https://repository.ugm.ac.id/digitasi/download.php?file=2349_Agus\%20Taufik\%20M.pdf

Mulyono, A. T., Kushari, B., \& Gunawan, H. E. (2009). Audit Keselamatan Infrastruktur Jalan (Studi Kasus Jalan Nasional KM 78-KM 79 Jalur Pantura Jawa, Kabupaten Batang). Journal of Civil Engineering, 16(3), 163-174. 
Pemerintah Kabupaten Lombok Barat. (2011). Rancangan Peraturan Daerah Kabupaten Lombok Barat Nomor 11 Tahun 2011 : Tentang Rencana Tata Ruang Wilayah Kabupaten Lombok Barat Tahun 2011-2031. Lombok Barat.

Sekretariat Negara. (2009). Undang-undang Republik Indonesia Nomor 22 Tahun 2009 tentang Lalu Lintas dan Angkutan Jalan. Jakarta.

Sukirman, S. (1999). Dasar-dasar Perencanaan Geometrik Jalan. Bandung: Penerbit Nova.

Sumarsono, A., Pramesti, F. P., \& Sarwono, D. (2010). Model Kecelakaan Lalulintas di Tikungan karena Pengaruh Konsistensi Alinyemen Horisontal dalam Desain Geometri Jalan Raya. Media Teknik Sipil, 10(2), 85-92.

Widianty, D., \& Alit, K. I. D. M. (2017). Karakterisasi Peluang dan Resiko Kecelakaan Lalu lintas pada Beberapa Segmen Ekstrim Ruas Jalan Senggigi-Pemenang. Jurnal Spektrum Sipil, 4(2), 142-150. 